\title{
Capnography-based analysis of dead space in rats during spontaneous breathing and mechanical ventilation
}

\author{
Dassow C., Schwenninger S., Runck H., Bühler S., Guttmann J. \\ Department of Experimental Anesthesiology, University Medical Center Freiburg, Germany \\ Constanze.Dassow@uniklinik-freiburg.de
}

\section{Introduction}

Measurement of carbon dioxide $\left(\mathrm{CO}_{2}\right)$ in exhaled gas volume (capnography) is a standard method to determine pulmonary dead space. Hereby, the dead space is calculated using a single breath diagram [1]. Unfortunately, most existing $\mathrm{CO}_{2}$ sensors do not work with the low tidal volumes found in small animals. Therefore, we designed a new setup for main stream capnography at small tidal volumes. Using this it was, for the first time, possible to determine differences in dead space during spontaneous breathing and mechanical ventilation in rats based on capnography.

\section{Methods}

$\mathrm{CO}_{2}$ concentration was measured by a novel, dead space minimized (additional dead space $=0.1 \mathrm{ml}$ ), main stream $\mathrm{CO}_{2}-$ sensor which was inserted between the endotracheal tube and the Y-piece. $40 \mathrm{Wistar}$ rats were grouped to different tidal volumes $\left(6,10\right.$ and $15 \mathrm{ml} / \mathrm{kg}$ body weight). $\mathrm{CO}_{2}$ and expiratory flow were recorded every 5 minutes for a time span of 1 minute. Dead space was analysed during spontaneous breathing and after switching to mechanical ventilation which was then sustained for an observation time of 1 hour.

\section{Results}

The dead space increased significantly by switching on mechanical ventilation. Hereby, a larger dead space corresponded to higher tidal volumes $(0.45 \pm 0.18 \mathrm{ml}$ at spontaneous breathing with an average tidal volume of $1.8 \mathrm{ml} ; 1.26$ $\pm 0.18 \mathrm{ml}$ at $6 \mathrm{ml} / \mathrm{kg}$ body weight; $1.31 \pm 0.09 \mathrm{ml}$ at $10 \mathrm{ml} / \mathrm{kg}$ body weight; $1.6 \pm 0.3 \mathrm{ml}$ at $15 \mathrm{ml} / \mathrm{kg}$ body weight).

\section{Conclusion}

Our setup is capable of measuring very low dead space volumes in rats. Dead space during mechanical ventilation was about 3 times higher compared to spontaneous breathing. Furthermore, the dead space increase was dependent on the tidal volume.

[1] Sinha, P et al., 2011, Intensive Care Med, 37:735-746. 